\title{
Derecho y Planificación Urbana. Problemas actuales de la planificación de Lima Metropolitana $\left(^{(*)}\right)^{* *}$
}

\section{Law and Urban Planning. Current problems in the planning of Metropolitan Lima}

\author{
Iván Ortiz Sánchez ${ }^{(* *)}$ \\ Pontificia Universidad Católica del Perú (Lima, Perú) \\ José Carlos Fernández Salas ${ }^{(+*+*)}$ \\ Pontificia Universidad Católica del Perú (Lima, Perú)
}

\author{
Andrés Devoto Ykeho ${ }^{(*+* t+x)}$ \\ Pontificia Universidad Católica del Perú (Lima, Perú)
}

\begin{abstract}
Resumen: Si bien la legislación urbana es un pilar fundamental para mejorar las condiciones de habitabilidad de las ciudades peruanas, en el caso de Lima Metropolitana el marco normativo de la planificación es, por decir lo menos, caótico e ineficaz. Por ello, el objetivo de este texto es describir y analizar el marco normativo del desarrollo urbano a nivel metropolitano con miras a que la legibilidad de las normas ayude a mejorar la formulación de políticas públicas y lineamientos para la planificación de la ciudad. Mediante análisis de gabinete, talleres y entrevistas no estructuradas hemos estudiado los antecedentes, actores e instrumentos del marco normativo de planificación urbana de Lima Metropolitana. Concluimos que actualmente este marco jurídico enfrenta desafíos críticos como la fragmentación administrativa y falta de visión de ciudad, la debilidad institucional y la carencia de sistematicidad en la normativa.
\end{abstract}

Palabras clave: Lima Metropolitana - Derecho urbanístico - Planificación urbana Zonificación - Gobernanza

${ }^{*}$ * Nota del editor: Este artículo fue recibido el 1 de septiembre de 2020 y su publicación fue aprobada el 26 de noviembre de 2020.

${ }^{* *}$ El presente artículo tiene su origen en una investigación realizada por encargo del Instituto Metropolitano de Planificación de Lima durante la gestión del director ejecutivo Augusto Mendoza Castillo. Asimismo, se nutrió del aporte del profesor Jorge Danós Ordoñez, del equipo de trabajo del Instituto Metropolitano de Planificación liderado por el director ejecutivo Augusto Mendoza Castillo, del equipo de trabajo de la Dirección de Urbanismo y Desarrollo Urbano de la Dirección General de Políticas y Regulación en Vivienda y Urbanismo del Ministerio de Vivienda, Construcción y Saneamiento liderado por la directora Tamara Alva Olórtegui y del abogado Ramón Chehade Herrera.

${ }^{* * *}$ Abogado por la Pontificia Universidad Católica del Perú (PUCP). Magíster en Derecho Constitucional y candidato a Doctor en Derecho de la PUCP. Profesor del Departamento de Derecho y Escuela de Posgrado de la PUCP donde enseña Derecho, Derecho Urbanístico y Legislación del Agua. Profesor asociado de la Academia de la Magistratura. Coordinador del Grupo de Investigación CONURB-PUCP. Miembro ordinario del Instituto Riva Agüero de la PUCP. ORCID: https://orcid.org/0000-0003-4096-2442. Correo electrónico: iortiz@pucp.edu.pe

${ }^{* * * *}$ Abogado por la Pontificia Universidad Católica del Perú (PUCP). Magíster en Planificación Urbana por la Universidad de Harvard. Profesor en la Facultad de Derecho de la PUCP y en las Facultades de Arquitectura de la PUCP y de la UNI. Investigador Principal del Grupo de Investigación CONURB-PUCP, del Grupo de Investigación Patrimonio Arquitectónico PUCP y del Grupo Peruano de Historia del Derecho del Instituto Riva-Agüero. ORCID: https://orcid.org/0000-0002-2371-2161. Correo electrónico: josec.fernandez@ pucp.edu.pe

$\left.{ }^{* * * * *}\right)$ Bachiller en Derecho por la Pontificia Universidad Católica del Perú (PUCP). Adjunto de Docencia en el curso Derecho Urbanístico en la Facultad de Derecho de la PUCP. Investigador Asociado del Grupo de Investigación CONURB-PUCP. ORCID: https://orcid. org/0000-0002-2309-0155. Correo electrónico: adevotoy@pucp.pe 


\begin{abstract}
Although urban legislation is fundamental to improve the living conditions of Peruvian cities, in the case of Metropolitan Lima the regulatory framework for urban planning is, to say the least, chaotic and ineffective. For this reason, in this paper we describe and analyze the regulatory framework of urban development at the metropolitan level with the objective that the legibility of the regulations helps to improve the design of public policies and guidelines for the planning of the city. Through cabinet analysis, workshops and unstructured interviews, we studied the history, actors and instruments of the urban planning regulatory framework of Metropolitan Lima. We conclude that this legal framework currently faces critical challenges such as administrative fragmentation and lack of vision of the city, institutional weakness and the lack of systematicity in the regulations.
\end{abstract}

Keywords: Lima - Zoning Law - Urban planning - Zoning Governance

\section{Introducción}

Cuando los abogados repiten la famosa frase de Kirchmann de que tres palabras rectificadoras del legislador convierten en desperdicio a bibliotecas enteras ${ }^{(1)}$, tienen en mente textos como este artículo. En las secciones siguientes describiremos el marco regulatorio de la planificación urbana en Lima Metropolitana, una normativa tan cambiante que en unos pocos años podría haber sido completamente reemplazada por nuevas normas. Sin embargo, sería un acontecimiento feliz que este marco regulatorio ya no se encuentre vigente, puesto que es posible que las normas de reemplazo sean instrumentos normativos más ordenados y sistemáticos como una Ley de Suelos, una Ordenanza Reguladora Metropolitana y un Plan de Desarrollo Metropolitano de Lima. Una normativa más ordenada y entendible será un paso importante para conseguir que las autoridades locales puedan realizar un manejo adecuado de una ciudad tan compleja como es el área metropolitana de Lima.

Lo que intentaremos hacer en este artículo es describir la situación actual de las normas que tienen que ver con la planificación urbana en Lima e identificar los problemas más críticos que requieren corregirse. En otros ámbitos normativos es sencillo proceder directamente a las críticas y propuestas que uno puede hacer para mejorar las instituciones jurídicas involucradas. No obstante, en el ámbito de la normativa metropolitana sobre planificación urbana creemos que antes de trabajar propuestas en concreto se requiere una previa descripción de las normas e instituciones en juego. Así, el objetivo de este artículo no es todavía el de desarrollar detalladamente las propuestas de reforma, lo que dejaremos para una segunda publicación. El objetivo del artículo es realizar un diagnóstico de la situación presente del marco regulatorio de la planificación urbana de Lima Metropolitana. Buscamos que este artículo sirva como base para facilitar una discusión más fructífera sobre este marco regulatorio entre los abogados especialistas y con profesionales de otras disciplinas.

Para cumplir con este objetivo el análisis no solo incluyó una revisión de escritorio de las ordenanzas de Lima metropolitana y las normas del gobierno nacional sobre planificación urbana. También incluyó la realización de entrevistas semiestructuradas con actores importantes en la gestión urbana de la ciudad, tanto del sector privado como de entidades del gobierno local y nacional. La investigación también se nutrió de la realización de talleres de discusión y análisis de la normativa metropolitana llevados a cabo con la participación de funcionarios de la Municipalidad Metropolitana de Lima y del Instituto Metropolitano de Planificación.

Los resultados de esta primera etapa de la investigación se desarrollan en este texto de la siguiente manera. En primer lugar, se incluyen unas breves notas sobre la situación de la planificación urbana en el Perú. Luego, se describe la evolución histórica de los planes de desarrollo urbano que se dieron para la ciudad de Lima. Posteriormente, se hace un análisis detallado de cuáles son los actores principales que tienen un rol en la planificación urbana y cuáles son los instrumentos técnico-normativos con los que estos cuentan. Finalmente, terminamos identificando cuáles son los principales desafíos de la normativa metropolitana de planificación, así como formulando algunos lineamientos y recomendaciones que serán materia de desarrollo en futuras publicaciones.

Somos de la idea que un marco regulatorio caótico y poco entendible (incluso para los especialistas) hace extremadamente difícil que la población pueda hacer suyas las normas y aplicarlas en su vida cotidiana. Esperamos que este artículo contribuya en ese acercamiento del Derecho con los ciudadanos.

(1) "Drei berichtigende Worte des Gesetzgebers, und ganze Bibliotheken werden zu Makulatur". 


\section{La planificación urbana en el Perú}

Las ciudades son una de las manifestaciones centrales de la vida en sociedad. Como tal, los problemas de las ciudades son tan complejos como los problemas de las sociedades mismas. Dicha complejidad se agrava por el hecho de que las decisiones de los residentes individuales de la sociedad se contraponen con los paradigmas a los que quiere tender una ciudad como conjunto. Por poner un ejemplo, es posible que la ciudad requiera que una zona incremente su densidad poblacional para dar una respuesta al incremento poblacional. Sin embargo, los ciudadanos de la zona pueden tener una oposición entendible a la densificación en razón a la pérdida de algunas comodidades que anteriormente gozaban en el área. La compatibilización de dichos intereses individuales con los fines de la ciudad como conjunto se da a través de la planificación urbana y esta última se materializa a través de un conjunto de instrumentos urbanos y jurídicos (Fernandez, 2018).

Desde el lado jurídico, la planificación urbana (o planeamiento urbano) es uno de los mejores ejemplos de ordenación del territorio que constituye una de las funciones que tiene el Estado. Así, podemos definir la planificación urbana como una competencia que ejerce la administración pública mediante procesos preestablecidos y sirve para definir objetivos, estrategias, metas y proyectos en cuanto a lo que será la ciudad o el espacio territorial que esta ocupa. Se manifiesta en planes y normas que tienen naturaleza pública por estar diseñadas en función al interés de la colectividad en general. El plan en sus diferentes modalidades y escalas es el instrumento básico de la ordenación del territorio y es sobre el que también se construye la función pública de la planificación en nuestro país (Ortiz, 2017, p.51). En ese sentido, los planes son la base necesaria y fundamental de toda ordenación del uso del espacio y del aprovechamiento de los recursos naturales.

En el aspecto jurídico, un sector de la doctrina propone que los planes tienen naturaleza de acto administrativo; sin embargo, no queda duda que en el ordenamiento jurídico peruano los planes tienen naturaleza de norma jurídica. Esto debido a que tienen la vocación de aplicación a una generalidad de casos y no a la situación particular de personas determinadas. Así, los instrumentos jurídicos de planificación urbana son aprobados por ordenanza municipal, instrumento que tiene el mayor rango normativo en el ámbito de su jurisdicción.

Por otra parte, una distinción que resulta importante hacer es entre la acción de planificar y la de gestionar. Como bien afirma Calderón (2017):

Planificar remite siempre al futuro, prever la evolución de un fenómeno o, más específico, simular el desdoblamiento de un proceso con el objetivo de prevenirse contra los probables problemas o, inversamente, sacar partido de los probables beneficios. La gestión, a diferencia, remite al presente, a administrar una situación dentro de los marcos de los recursos disponibles y en vista de las necesidades inmediatas. La gestión es la administración de los recursos y de las relaciones de poder aquí y ahora. En teoría la planificación define y marca el camino de la gestión (pp. 225-226).

En ese marco conceptual, pertenece al ámbito de la planificación el desarrollo de instrumentos normativos como los planes de acondicionamiento territorial, los planes de desarrollo metropolitano, los planes de desarrollo urbano y los planes específicos de una ciudad. Dichos instrumentos normativos tienen la vocación de establecer los lineamientos obligatorios bajo los cuales se tiene que producir el crecimiento y desarrollo de un área urbana. Por otro lado, pertenece al ámbito de la gestión urbana la actividad de otorgamiento de títulos habilitantes autorizando a los privados a habilitar o a edificar, así como la de controlar el cumplimiento de las referidas autorizaciones.

Evidentemente, planificación y gestión se encuentran íntimamente relacionadas, ya que la actividad de controlar y fiscalizar las acciones particulares de los ciudadanos se hace en base a los planes a corto, mediano y largo plazo que la ciudad haya establecido. En la línea de lo señalado, en este artículo nos vamos a referir principalmente a la actividad de planificación a cargo de los gobiernos locales y, en particular, de la Municipalidad Metropolitana de Lima.

\section{El marco normativo de la planificación en Lima Metropolitana}

Como una cuestión previa, hay que mencionar que, además del marco metropolitano de planificación, existe un marco normativo nacional, que se basa en las siguientes normas: la Constitución Política Peruana (1993), la Ley Orgánica de Municipalidades (2003) y el Reglamento de Acondicionamiento Territorial y Desarrollo Urbano Sostenible RATDUS (2016). En cuanto a la Constitución, esta determinó una estructura donde los gobiernos locales promueven el desarrollo 
y la economía local en armonía con las políticas y planes nacionales (Artículo 195). Para ello, tanto municipalidades provinciales como locales son competentes para planificar el desarrollo urbano y rural dentro de sus circunscripciones, incluyendo la zonificación, urbanismo y el acondicionamiento territorial (artículo 195, numeral 6).

Asimismo, la Constitución es importante porque le da a Lima, como Capital de la República, un régimen especial en las leyes de descentralización y en la Ley Orgánica de Municipalidades. Lima como Capital (Artículo 198) no integra ninguna de las regiones del Perú. Así, la Municipalidad Metropolitana de Lima es el equivalente a una municipalidad provincial que, además, ejerce competencias de gobierno regional sin constituirse propiamente en una región. Por lo demás, de acuerdo con el artículo 70 de la Constitución, la propiedad es un derecho limitado, que debe ejercerse en armonía con el bien común y cuyas limitaciones de orden urbanístico se encuentran desarrolladas incluso en el propio Código Civil (Fernández \& Pinedo, 2020).

Luego tenemos la Ley Orgánica de Municipalidades. Esta norma desarrolla constitucionalmente las funciones y competencias urbanas de los gobiernos locales y forma parte del bloque de constitucionalidad. A grandes rasgos, esta ley ha establecido que las municipalidades provinciales planifiquen el territorio aprobando instrumentos como el Plan de Acondicionamiento Territorial (PAT), Planes de Desarrollo Urbano (PDU), Planes Específicos y demás. Por su parte, las municipalidades distritales aprueban sus Planes Urbanos Distritales en sujeción a los planes aprobados por las municipalidades provinciales y tienen como función específica exclusiva el otorgamiento de actos administrativos como licencias de habilitación urbana, edificación y funcionamiento.

Finalmente tenemos al RATDUS (2016). Este dispositivo es el que orienta los procedimientos técnicos y administrativos que deben seguir las municipalidades para ejercer sus funciones, a fin de garantizar la correcta aprobación de los planes de desarrollo que regulan el ámbito urbano. En este reglamento, al igual que sus antecedentes, se regula los distintos planes urbanísticos, sus contenidos, los procesos de aprobación, la zonificación y el procedimiento de cambio de zonificación. Con base en este contexto normativo, pasaremos a concentrarnos en el caso particular de Lima Metropolitana.

\subsection{Antecedentes al marco metropolitano}

Desde el punto de vista histórico, existen cuatro momentos claves que marcaron un hito en la evolución de la planificación de nuestra área metropolitana. El primer momento es la estructuración del Plan Sada-Meiggs de 1876, uno de los primeros planes de Lima. Dados los problemas de hacinamiento y tugurización en la segunda mitad del siglo XIX que derivaron en problemas sanitarios, el gobierno del presidente José Balta y Montero encargó al agrónomo Sada di Carlos la elaboración del plano topográfico de Lima y de su plan regulador. Posteriormente, el gobierno contrataría al ingeniero Henry Meiggs para elaborar y ejecutar la propuesta del plano topográfico de Lima. Dada la alta congestión de actividades, personas y tráfico en centro de la ciudad, este plan pretendió ordenar el crecimiento y desconcentrar la ciudad, definiendo así la primera expansión de Lima hacia el sur y el suroeste del valle del Rímac (Vega et al., 2019, pp. 26-27).

El segundo momento clave para entender la planificación metropolitana es la aprobación del Plan Piloto de Lima. Este fue elaborado por la Oficina Nacional de Planeamiento y Urbanismo (en delante, ONPU) y aprobado por la Resolución Suprema 258 del Ministerio de Fomento y Obras Públicas en setiembre de 1949. Para entender el contexto, la ONPU fue creada mediante la Ley 10723 del Congreso de la República un 30 de diciembre de 1946 durante el gobierno del presidente José Luis Bustamante y Rivero. Según Harris y Hosse, citados por Kahatt (2015) la ONPU fue uno de los primeros organismos nacionales de planificación física establecidos en América Latina (p.110). Esta Oficina, parte del Ministerio de Fomento y Obras Públicas, fue un ente coordinador y dirigía la labor urbanística de las reparticiones técnicas del gobierno y los municipios. Asimismo, mientras la ONPU se encargaba de estudiar y formular los planes reguladores y de extensión de las ciudades y pueblos de la República, el entonces vigente Consejo Nacional de Urbanismo, conformado por distintos órganos del gobierno como por la sociedad civil, es el que examinaba, observaba y aprobaba los proyectos de planes con carácter de recomendación técnica que trabajaba la ONPU.

Así, en un contexto posterior al terremoto de 1940 y de clara influencia del urbanismo funcionalista de principios del siglo $X X$, este incide básicamente en aspectos físicofuncionales y de diseño urbano (Castillo, 2013, p. 23). Dos características importantes del Plan Piloto fueron que, primero, las avenidas adquirieron gran relevancia como ejes articuladores de la expansión urbana y, segundo, se definieron usos del suelo según 


\section{Iván Ortiz Sánchez \\ José Carlos Fernández Salas \\ Andrés Devoto Ykeho}

grandes funciones: habitar, trabajar y recrearse, conectados por la circulación (Vega et al., 2019, p. 27).

El tercer momento clave es el nacimiento del Plan de Desarrollo Metropolitano de Lima-Callao 1968-1980, formulado también por la ONPU entre 1965 y 1968, pero ahora en convenio con la Municipalidad de Lima durante la administración de Luis Bedoya Reyes. Este plan se planteó en un contexto de crecimiento expansivo de la ciudad causado por la explosión demográfica de las migraciones hacia Lima y la fuerte escasez de servicios básicos y equipamientos urbanos. Como consecuencia de ello, una de las propuestas de este plan fue permitir el uso urbano a los valles próximos de Lima, fomentando así una expansión sin precedentes, y de muy baja densidad (Vega et al., 2019, p. 25). Como veremos posteriormente, este tipo de crecimiento urbano pondrá a prueba los tres niveles de regulación de los suelos metropolitanos.

De los tres planes descritos hasta el momento, una característica común que encontramos es que fueron formulados por instancias ajenas al nivel local. Los tres fueron fomentados y formulados por las instancias más altas de gobierno. El primero, por una decisión política de alto nivel. Los dos siguientes, por la ONPU, que formaba parte del Ministerio de Fomento y Obras Públicas. Asimismo, en la formulación de los planes antes descritos, estos sugerían en los planos de zonificación mayores densidades en los distritos de menor valor comercial y no en las "mejores zonas". Según Calderón, ello era una clara muestra de la influencia del modernismo del arquitecto Le Corbusier y el Congreso Internacional de Arquitectura Moderna en las entidades antes mencionadas, pues tanto el Concejo Nacional de Urbanismo como la ONPU creían que la solución a los problemas de vivienda eran los edificios en departamentos (2017, p. 127).

El cuarto y último hito en este recuento histórico es el Plan de Estructuración Urbana Metropolitana de Lima 1986-1996. Este plan elaborado esta vez por la Municipalidad Metropolitana de Lima fue aprobado mediante Acuerdo de Concejo 2701986 durante la administración de Alfonso Barrantes Lingán. Según Dorich, citado por Vega y otros (2019, p. 25) fueron 3 rasgos que distinguen a este instrumento. En cuanto a su formulación, este consideró una metodología participativa en su elaboración. En cuanto a sus propuestas, si bien estuvo orientado principalmente a subsanar el déficit de vivienda y de servicios básicos, también planteó la idea de corredores para el transporte público. Sin embargo, respecto a sus deficiencias, esta propuesta se hizo sin una idea de metrópoli. Asimismo, tuvo importantes limitaciones para implementarse debido a la violencia política de la década de los 1980s. Por el contrario, para Castillo (2013, p. 24) este constituyó un proyecto piloto que no llegó a ser un plan metropolitano propiamente. Se critica, además, que la dimensión ambiental y de seguridad física ante desastres no se hayan desarrollado como ejes centrales. Se señala que las propuestas del plan se centraron en algunas políticas respecto del suelo y respecto de infraestructura de servicios.

Es así como llegamos al último plan aprobado en Lima Metropolitana que es el Plan de Desarrollo Metropolitano Lima - Callao (PLANMET 1990-2010), que con sustanciales transformaciones rige hasta la actualidad. Este plan fue formulado entre 1987 y 1989 por el Proyecto Especial PLANMET de la Municipalidad de Lima, aprobado mediante Acuerdo de Concejo 287-1989 durante la gestión del alcalde Jorge del Castillo. Este plan sería puesto en vigencia por Decreto de Alcaldía 127-1992 durante la administración del alcalde Ricardo Belmont y ratificado por Ordenanza 099-1996 durante la gestión del alcalde Alberto Andrade (Castillo, 2013, p. 24).

Según Dorich, citado por Vega y otros (2019, p. 25), este plan siguió una lógica expansiva urbana que reiniciaría la dinámica inmobiliaria, dejando al mercado gran parte del ordenamiento de la ciudad, pero considerando como principales polos de desarrollo de la ciudad los centros industriales. Para Castillo (2013, p. 24) este fue el primer antecedente de planificación urbana ambiental por haber incorporado un enfoque de desarrollo urbano sostenible. Es importante mencionar que fue con motivo de este plan que también entró en funciones el actual organismo encargado de la planificación urbana en Lima que es el Instituto Metropolitano de Planificación.

La vigencia de este plan ha sido prorrogada tres veces en la gestión de la alcaldesa Susana Villarán mediante las Ordenanzas Municipales 1505, 1604 y 1702. La última prórroga establecida por la Ordenanza 1702 estableció la vigencia del PLANMET 19902010 hasta la aprobación del nuevo Plan de Desarrollo Metropolitano. Así, la propuesta conocida como el PLAM2035 en la que trabajaba la gestión de Susana Villarán nunca llegó ser un instrumento aprobado debido al cambio de gestión municipal. Por ello, el PLANMET 1990-2010 es el instrumento vigente en nuestra ciudad hasta que tengamos la aprobación de un nuevo Plan Metropolitano, tarea en la que se encuentra 
embarcado el Instituto Metropolitano de Planificación en la gestión del actual alcalde Jorge Muñoz.

\subsection{Actores de la planificación metropolitana}

Los actores que juegan un rol clave en el desarrollo de la normativa metropolitana sobre planificación urbana son (i) el Instituto Metropolitano de Planificación (en adelante, IMP), el (ii) Concejo Metropolitano y la (iii) Gerencia de Desarrollo Urbano (en adelante, GDU). El 07 de febrero de 1991, mediante Acuerdo de Consejo 032, se creó el Instituto Metropolitano de Planificación. Posteriormente, mediante Acuerdo de Concejo 119 se aprobó su estatuto. Fue el PLANMET 1990-2010 el que recomendó la necesidad de constituir un organismo técnico encargado de la planificación urbana. Así, se decía en esos años que con el IMP:

(...) se cristaliza una de las propuestas importantes del Plan de Desarrollo Metropolitano 1990-2010, que establece la necesidad de crear un organismo técnico permanente que se encargue de formular, evaluar y actualizar los Planes de Desarrollo Local que señala la Ley Orgánica de Municipalidades $\mathrm{N}^{\circ} 23853$, a fin de promover un desarrollo planificado de la Provincia de Lima (Municipalidad Metropolitana de Lima, 1992, p. 44).

En ese sentido, en la actualidad es a través del IMP que la Municipalidad Metropolitana de Lima planifica el desarrollo urbano territorial. Según el artículo 5 de su Reglamento de Organización y Funciones, el IMP promueve, formula, conduce, supervisa y evalúa permanentemente la gestión, ejecución y/o actualización de los planes de desarrollo local. En otras palabras, el IMP es el organismo técnico que lidera el proceso de elaboración de los distintos planes de alcance metropolitano. Asimismo, monitorea y hace el seguimiento a la implementación de los planes ya existentes. Ahora bien, aunque el IMP es fundamental para el proceso de formulación de planes metropolitano, este organismo requiere del Concejo Metropolitano para la aprobación política y normativa de los instrumentos oficiales de planificación.

El Concejo Metropolitano de Lima es el máximo órgano representativo de la comuna. El Concejo Metropolitano está conformado por el pleno y sus comisiones. Así, en primer lugar, el pleno está integrado por el alcalde y los 39 regidores electos por la ciudadanía. Según el Reglamento Interior del Concejo Metropolitano de Lima (Ordenanza 571), este órgano tiene principalmente dos funciones: la función normativa y fiscalizadora. Respecto a la primera, esta comprende la iniciativa legislativa, debate y aprobación de ordenanzas, acuerdos, resoluciones y otros instrumentos, para materias de distinto tipo entre las que se incluye el acondicionamiento territorial y el desarrollo urbano.

En relación a las comisiones, estas son grupos de trabajo conformados por regidores y establecidos por el pleno del
Concejo. Las comisiones tienen 2 funciones básicamente: (i) estudio y elaboración de propuestas y (ii) absolución de consultas en los asuntos de su especialidad. En la misma línea, las comisiones pueden ser ordinarias y especiales. Mientras las primeras están encargadas del estudio y dictamen de los asuntos ordinarios de la agenda del Concejo, las segundas se instauran con fines protocolares, de estudios e investigaciones y también pueden avocarse a actividades de fiscalización de carácter puntual según acuerde el pleno.

La comisión ordinaria que es competente para ver los temas relacionados a la planificación urbana es la Comisión Metropolitana de Desarrollo Urbano, Vivienda y Nomenclatura. El artículo 34 del Reglamento Interior del Concejo Metropolitano de Lima contiene una lista detallada de asuntos de su competencia. Cuadro 1:

Estos temas mencionados en el cuadro no son una lista cerrada. El mismo Reglamento Interior del Concejo establece la posibilidad que la Ley Orgánica de Municipalidades, otras normas de carácter municipal o regional o el mismo Concejo amplíen la lista de asuntos que requieren pronunciamiento de la Comisión Metropolitana de Desarrollo Urbano, Vivienda y Nomenclatura. Con relación a estos asuntos mencionados y los futuros por establecer, esta comisión ordinaria puede ejercer las siguientes funciones específicas:

- Dictaminar sobre proyectos normativos; informes, proposiciones y pedidos de regidores; e iniciativas de organismos vecinales.

- Elaborar, actualizar, revisar y propone políticas generales y normas necesarias del Concejo.

- Efectuar investigaciones y estudios.

- Demás que le encargue el Concejo.

Ahora bien, al ser la aprobación de planes urbanos y las asignaciones de zonificación en la ciudad un acto de gobierno y no un acto administrativo, se requiere la intervención directa del Concejo Metropolitano para dichas aprobaciones. Luego de que el IMP hace las evaluaciones técnicas pertinentes y finalice los procedimientos de consulta 
Cuadro 1

\begin{tabular}{|c|c|}
\hline Asuntos & Detalle \\
\hline $\begin{array}{l}\text { Acondicionamiento } \\
\text { Territorial, Planificación } \\
\text { Urbana Metropolitana y } \\
\text { zonificación }\end{array}$ & $\begin{array}{l}\text { - Acondicionamiento Territorial a nivel provincial } \\
\text { - Planificación Urbana Metropolitana, integrando el } \\
\text { desarrollo urbano de los distritos que conforman la } \\
\text { metrópoli } \\
\text { - Expansión y desarrollo urbano } \\
\text { - Zonificación } \\
\text { - Usos del Suelo }\end{array}$ \\
\hline $\begin{array}{l}\text { Planes Metropolitanos } \\
\text { Complementario }\end{array}$ & $\begin{array}{l}\text { - Plan Metropolitano de Vías e Infraestructura Urbana } \\
\text { - Plan Metropolitano de Equipamiento y Servicios } \\
\text { Urbanos } \\
\text { - Plan Metropolitano de Parques y Recreación }\end{array}$ \\
\hline $\begin{array}{l}\text { Áreas de Tratamiento } \\
\text { Especial }\end{array}$ & $\begin{array}{l}\text { - Desarrollo del Centro Histórico de Lima y de los } \\
\text { Centros Históricos Distritales } \\
\text { - Zonas Monumentales y Monumentos Culturales, } \\
\text { Históricos Arquitectónicos. } \\
\text { - Renovación Urbana } \\
\text { - Zonas y áreas ribereñas del litoral de la Metrópoli } \\
\text { - Proyecto de la Costa Verde }\end{array}$ \\
\hline $\begin{array}{l}\text { Títulos habilitantes } \\
\text { y procedimientos } \\
\text { Administrativos } \\
\text { Urbanos }\end{array}$ & $\begin{array}{l}\text { - Habilitaciones Urbanas } \\
\text { - Licencias de obra de construcción, remodelación, } \\
\text { restauración y demolición } \\
\text { - Anuncios y publicidad exterior } \\
\text { - Asistencia técnica, capacitación, investigación } \\
\text { científica y tecnológica en materia de construcción, } \\
\text { habilitación urbana y saneamiento }\end{array}$ \\
\hline Vivienda & $\begin{array}{l}\text { - Políticas, planes y programas de vivienda y de } \\
\text { saneamiento en la Metrópoli, priorizando a los sectores } \\
\text { en riesgo social } \\
\text { - Proyectos habitacionales del sector público y privado } \\
\text { - Asentamientos Humanos Marginales }\end{array}$ \\
\hline $\begin{array}{l}\text { Sistemas de } \\
\text { Información Urbana y } \\
\text { Nomenclatura }\end{array}$ & $\begin{array}{l}\text { - Catastro Urbano Metropolitano } \\
\text { - Sistemas de información sobre planificación, } \\
\text { zonificación y administración del desarrollo urbano } \\
\text { de la Metrópoli } \\
\text { - Nomenclatura de la red vial metropolitana, parques, } \\
\text { áreas verdes y de recreación pública }\end{array}$ \\
\hline $\begin{array}{l}\text { Bienes de Dominio } \\
\text { Público }\end{array}$ & $\begin{array}{l}\text { - Terrenos Eriazos } \\
\text { - Bienes de propiedad Estatal }\end{array}$ \\
\hline Demarcación Territorial & - Delimitación de jurisdicciones distritales \\
\hline
\end{tabular}

respecto a los procesos de planificación, es el Concejo el que procede con la aprobación de normativa de la ordenanza en la que un determinado plan está contenido. Abordaremos esto detalladamente más adelante.

Por último, la GDU es un órgano de línea que tiene dos tipos de funciones y atribuciones. Por el lado de las atribuciones relacionadas directamente a la planificación, vemos que la GDU puede formular y evaluar planes urbanos específicos. Antecedente ello fue el Proyecto de Plan Específico de Barrios Altos (Cercado de Lima y El Agustino) 2014-2025. Pero, si bien la GDU tiene posibilidad de formular propuestas y estrategias de intervención en áreas de tratamiento especial, este es un órgano principalmente de gestión urbana abocado al "día a día".

A diferencia del IMP que tiene una mirada prospectiva y a largo plazo, la GDU mediante sus 4 subgerencias conduce y supervisa, por ejemplo, procedimientos para la obtención de títulos habilitantes como los de habitación urbana y edificaciones, aprueba independizaciones de terrenos rústicos y estudios de impacto vial, gestiona procesos de saneamiento físico legal y renovación urbana, otorga certificaciones urbanas, entre otras funciones.

Si bien estas funciones son de gestión urbana, la GDU tiene atribuciones que tienen repercusiones directas y de gran relevancia en la planificación a nivel metropolitana. Así como el IMP define y marca el camino de la gestión metropolitana, la GDU debe aprobar licencias o dar certificados de conformidad con los planes y ordenanzas formuladas por el IMP y aprobadas por el Concejo Metropolitano. Un óptimo desempeño de este órgano de línea puede contribuir en gran medida a la consecución de las metas y objetivos de largo de plazo aprobados por los distintos instrumentos de planificación.

\subsection{Instrumentos de planificación y gestión urbana}

Como se ha señalado previamente, en la actualidad se encuentra vigente el Plan de Desarrollo Metropolitano Lima-Callao (PLANMET 1990-2010), el mismo que ha sido objeto de una serie de modificaciones en las últimas décadas. Sin embargo, para entender la metodología bajo la cual se da la regulación sobre la planificación y gestión urbana es necesario tomar en cuenta las Ordenanzas 620-MML y 1862-MML.

La Ordenanza 620-MML, publicada el 4 de abril del 2004, fue la norma reglamentaria de proceso de aprobación de instrumentos de planificación y actualización de la zonificación de los usos del suelo de Lima Metropolitana. Esta ordenanza reguló principalmente el contenido y proceso de aprobación de cuatro instrumentos de planificación urbana: el plan 
metropolitano de acondicionamiento territorial, el de desarrollo urbano, los planes específicos y los urbano distritales. Asimismo, la ordenanza dispuso lineamientos generales de la zonificación de los usos del suelo y reglamentó los procedimientos de cambio de zonificación y los reajustes integrales de zonificación. La Ordenanza 620-MML fue derogada y dejada sin efecto por la Ordenanza 1862 a excepción de su artículo 30 , que se refiere a las características técnicas para el uso del suelo en las distintas zonas de la ciudad.

Publicada el 28 de diciembre del 2014, la Ordenanza 1862MML es el dispositivo de mayor importancia para la planificación urbana en el área metropolitana de Lima en la actualidad. Esta norma, en contraste con su predecesora, regula no solo instrumentos de planificación urbana sino también instrumentos de gestión urbana. Sobre los últimos, la norma ha previsto el desarrollo de 4 temas primordiales para la gestión como son la (i) coordinación metropolitana, el (ii) control y fiscalización, el (iii) financiamiento y los proyectos urbanos y el (iv) equipamiento urbano. En la misma línea, la Ordenanza 1862 ya no regula el procedimiento de cambio de zonificación. Actualmente esta regulación es materia de una ordenanza independiente ${ }^{(2)}$, la cual detallaremos posteriormente.

El procedimiento establecido normativamente para formular y aprobar planes urbanos en nuestra capital varía dependiendo del instrumento que se aprueba; sin embargo, hay muchos aspectos en común. A grandes rasgos podríamos afirmar que estos procedimientos tienen dos fases: la exhibición y aprobación.

La fase de exhibición es dirigida por los gobiernos locales ${ }^{(3)}$ y tiene un plazo de 30 días calendario ${ }^{(4)}$. En este corto plazo, se deben realizar dos acciones en concreto. En primer lugar, se debe exhibir las propuestas preliminares de los distintos planes urbanos físicamente en los locales municipales y sedes de organizaciones vecinales; $y$ virtualmente en las páginas web institucionales de las municipalidades. En segundo lugar, en estos mismos 30 días calendario el municipio correspondiente debe realizar audiencias o exposiciones técnicas con actores involucrados ${ }^{(5)}$ con el objetivo de socializar la propuesta y recibir sus observaciones y recomendaciones debidamente sustentadas.

Finalizados los 30 días calendario para la exhibición, el Equipo Técnico de la municipalidad responsable de la elaboración del plan, en un plazo de 15 días calendario, debe analizar las recomendaciones y observaciones recibidas con la finalidad de incluirlas o desestimarlas en un pronunciamiento fundamentado. Vale recalcar que las opiniones que ejerza la ciudadanía no son de carácter vinculante. Este pronunciamiento contenido en un informe se envía a los órganos deliberativos del gobierno local correspondiente, dando fin a la fase de exhibición.

Respecto a la fase de aprobación, a diferencia de la fase de exhibición, esta no tiene un plazo establecido en la normativa urbana porque, como mencionamos anteriormente, es un acto de gobierno. Asimismo, esta fase se encuentra enteramente en el Concejo Metropolitano, máximo órgano deliberativo de la corporación metropolitana conformado por representantes políticos directamente elegidos por la ciudadanía.

Las propuestas enviadas por el IMP o la municipalidad distrital correspondiente, antes de ser aprobadas mediante Ordenanza, deben pasar por la Comisión Metropolitana de Desarrollo Urbano, Vivienda y Nomenclatura para su estudio y posterior dictamen ${ }^{(6)}$. Esta comisión emitirá un dictamen que debe contener una exposición documentada, precisa y clara de los estudios que realizaron sobre la proposición de Ordenanza que apruebe los distintos planes urbanos; así como conclusiones y recomendaciones

(2) Ordenanza 2086-MML

(3) El IMP es exhibe la propuesta de PMDU y de Planes Específicos. Respecto al Plan Urbano Distrital, la exhibición es dirigida por la municipalidad distrital correspondiente.

(4) Literal a del artículo 11 de la Ordenanza 1864-MML, numeral 1 del artículo 25 de la Ordenanza 1864-MML y literal a del artículo 30 de la Ordenanza 1864-MML.

(5) La normativa metropolitana menciona una multiplicidad de actores muy diversos, entre los cuales están organizaciones de la sociedad civil; instituciones representativas del sector empresarial, laboral y profesional; propietarios y usuarios de inmuebles localizados dentro del área del plan, otros gobiernos locales; etc.

(6) El literal a del artículo 83 del Reglamento Interno del Concejo permite que otra Comisión, aparte de la Comisión Metropolitana de Desarrollo Urbano, Vivienda y Nomenclatura, solicite estudiar la proposición. Lo normal es que lo vea solo una Comisión; sin embargo, el Concejo puede decidir lo contrario. Un ejemplo reciente de ello es el pedido de la Comisión de Medio Ambiente, Salud y Bienestar Social de revisar la propuesta de cambio de zonificación del distrito de Lurín. Este cambio fue criticado por afectar gravemente el paisaje, los humedales y las tierras agrícolas del último valle verde de Lima en el entorno del Santuario de Pachacamac (SPDA Actualidad Ambiental, 2020). 


\section{Iván Ortiz Sánchez \\ José Carlos Fernández Salas \\ Andrés Devoto Ykeho}

derivadas de este estudio(7). Estos dictámenes pueden concluir aprobar el plan urbano, aprobarlo con modificaciones, desaprobarlo, requerir un estudio más profundo o solicitar un plazo adicional para expedirlo. Emitido el dictamen y agendado el punto en la agenda del Concejo, este pasará a debatir y votar por la propuesta de ordenanza que contiene el plan urbano.

Siendo los gobiernos locales canales inmediatos de participación vecinal en los asuntos públicos, estos actúan en base a una legislación que de facto no permite un proceso real de participación. En una ciudad con casi 10 millones de habitantes, 30 días calendario parece ser un plazo inadecuado para recoger las opiniones de la ciudadanía(8). Otro punto importante a comentar es que el plazo de 30 días calendario aplica para todos los planes, independientemente de la escala de acción u objeto de regulación. Convendría analizar si cada proceso requiere plazos diferenciados dependiendo la escala o complejidad del plan. Por lo tanto, urge sincerar estos plazos para que la ciudadanía sea realmente escuchada. Solo así los planes dejarán de ser documentos inoperantes sin legitimidad para convertirse en verdaderos pactos o acuerdos entre todos los actores involucrados (sociedad civil, Estado, sector empresarial).

\subsection{Clasificación del uso del suelo}

La legislación urbana metropolitana, con el objetivo de regular el uso del suelo e intervenir en el territorio, clasifica y ordena el espacio de Lima en tres niveles. El primero de todos son las Condiciones Generales de Uso. El primer antecedente de este concepto lo encontramos en el PLANMET 1990-2010, donde se clasificó el suelo del área metropolitana en (i) urbano, (ii) urbanizable y (iii) no urbanizable. Posteriormente, la Ordenanza 228-MML cambió esta clasificación por una división que define (i) áreas urbanas y de (ii) expansión urbana.

El Área Urbana es considerada como tal por estar definida en el Plano de Zonificación General de Lima Metropolitana y por ende destinarse a usos residenciales, comerciales industriales, recreacionales, parques zonales, equipamiento urbano, ZRE y otros. Por el contrario, se considera Área de Expansión Urbana a toda aquella que comprende territorios previstos para el futuro crecimiento de la Metrópoli, así como aquellos territorios de entorno necesarios para proporcionar a su población las mejores condiciones ambientales, de seguridad y de habitabilidad.

Adicionalmente, las Áreas de Expansión Urbana se subclasifican en tres tipos de áreas. La primera es el Área de Crecimiento Urbano para la expansión a corto, mediano y largo plazo. Las siguientes dos áreas son de carácter no urbanizable. Por un lado, tenemos las Áreas de Protección por Función Ambiental y Recreativa, pertenecientes a los ecosistemas de los valles de los ríos Chillón, Rímac y Lurín. Estas áreas actúan como fuentes de oxigenación y recarga del acuífero y deben ser destinadas a fines agrícolas, forestales, recreativos y culturales, de investigación, paisajísticos y aquellos que definan los estudios posteriores.

Por otro lado, tenemos las áreas de Amortiguamiento, Seguridad y Paisaje Natural. Esta área es definida por la Ordenanza 229. MML como aquella franja que bordea el área urbana y de crecimiento urbano de Lima. La Ordenanza determinó que estas áreas solo podrán destinarse a arborización, paisajismo, turismo y otras obras de defensa con fines de protección física y control de eventos de geodinámica externa.

El reto que enfrenta la aplicación de estas clasificaciones es el crecimiento informal que ha configurado la forma urbana de nuestra capital. Según el Primer Reporte Nacional de Indicadores Urbanos 2018, Lima ha añadido 907 hectáreas por años de suelo urbano en el periodo de 2009-2018 (Zucchetti \& Freundt, 2019 , p. 67). Otros estudios estiman que, en términos absolutos, entre 2000 y 2018 Lima generó 25.000 has de suelo urbano, siendo la ciudad que más suelo urbano generó en el país (Espinoza \& Fort, 2020, p. 8). Actualmente, Lima tiene una superficie urbana equivalente a la suma de la superficie de las 18 ciudades capitales que la siguen en tamaño (Zucchetti \& Freundt, 2019, p. 67). La magnitud del crecimiento informal y desordenado pone en cuestión todas estas calificaciones, en especial las áreas de carácter no urbanizable que puede ser presionada por el crecimiento mencionado.

\section{5. Áreas de tratamiento normativo}

Como segundo gran nivel de clasificación tenemos a la estructuración urbana del área

(7) Literal a del artículo 77 de la Ordenanza 571.

(8) La derogada Ordenanza 620-MML establecía plazos más realistas. Para la aprobación del Plan Metropolitano se estipulaba 150 días calendario para su aprobación, de los cuales 90 días calendario eran solo para la exhibición. Posteriormente, la municipalidad tenía 60 días calendario para desestimar o incluir recomendaciones. Para los planes específicos y urbano distritales se daba 90 días calendario, de los cuales 60 eran solo para exhibición y 30 para desestimar o concluir recomendaciones. 
de la metrópoli. De conformidad con el RATDUS, entendemos que dicha estructuración responde a la identificación de áreas homogéneas y a la clasificación del suelo que permita orientara las áreas para actuaciones e intervenciones urbanísticas.

Actualmente la estructuración urbana metropolitana se materializa en cuatro áreas de tratamiento normativo (ATN I, ATN II, ATN III y ATN IV). EI Reajuste Integral de la Zonificación de los Usos del Suelo de Lima Metropolitana, aprobado por las Ordenanza 620-MML y 719-MML, fue el documento que propuso estas cuatro áreas, las cuales dividen las zonas de la ciudad según su consolidación urbana, la especialización funcional y el grado de residencialidad. Estas áreas se aplicaron a partir del último Reajuste Integral de Zonificación de los Usos que abarcó todos los distritos de Lima Metropolitana en el periodo 2005-2008. Sus características son las siguientes:

\begin{tabular}{|c|c|c|c|}
\hline Área I & $\begin{array}{l}\text { - Densificación } \\
\text { regulada } \\
\text { - Mayor } \\
\text { compatibilidad con } \\
\text { otras actividades }\end{array}$ & $\begin{array}{l}\text { Distritos: Carabayllo, Puente Piedra, } \\
\text { Comas, Los Olivos, Independencia, San } \\
\text { Martín de Porres, Rímac (P), Cercado } \\
\text { de Lima (P), El Agustino, San Juan de } \\
\text { Lurigancho, Ate (P), Santa Anita, San } \\
\text { Juan de Miraflores, Villa María del Triunfo, } \\
\text { Villa El Salvador }\end{array}$ & $\begin{array}{l}\text { Ámbito de } \\
\text { aplicación } \\
\text { de la } \\
\text { Ordenanza } \\
\text { No. } 620\end{array}$ \\
\hline Área II & $\begin{array}{l}\text { - Mayor } \\
\text { densificación } \\
\text { - Compatibilidad } \\
\text { regulada con otras } \\
\text { actividades }\end{array}$ & $\begin{array}{l}\text { Distritos, San Miguel, Pueblo Libre, } \\
\text { Magdalena (P), Breña, Lince, Jesús } \\
\text { María, La <victoria, San Luis, Cercado } \\
\text { (P), Barranco, Cforrillos (P), Surquillo } \\
\text { (P), Rímac (P), San Borja (P), Santiago } \\
\text { de Surco (P). }\end{array}$ & \\
\hline Área III & $\begin{array}{l}\text { - Densificación } \\
\text { regulada } \\
\text { - Restricción a la } \\
\text { compatibilidad con } \\
\text { otras actividades }\end{array}$ & $\begin{array}{l}\text { Distritos: La Molina, Santiago de Surco } \\
\text { (P), San Borja (P), San Isidro, Miraflores, } \\
\text { Magdalena (P), Surquillo (P). }\end{array}$ & \\
\hline Área IV & $\begin{array}{l}\text { Reglamentación } \\
\text { especial } \\
\text { - Centro histórico } \\
\text { - Zonas } \\
\text { Monumentales } \\
\text { - Zonas de Valles } \\
\text { - Zonas Ecológicas } \\
\text { - Zonas de } \\
\text { Balnearios }\end{array}$ & $\begin{array}{l}\text { Distritos: Cercado (P), Rímac (P), } \\
\text { Chorrillos )P), Carabayllo, Puente Piedra, } \\
\text { Lurigancho (P), Chaclacayo (P), Lurín } \\
\text { (P), Punta Hermosa, Punta Negra, } \\
\text { San Bartolo, Santa María, Pucusana, } \\
\text { Pachacamac, Cieneguilla, Ancón (P), } \\
\text { Santa Rosa (P). }\end{array}$ & $\begin{array}{l}\text { Ámbito de } \\
\text { aplicación } \\
\text { de normas } \\
\text { específicas }\end{array}$ \\
\hline
\end{tabular}

$(P)=$ Parcial

En cuanto a las ATNs, Mendoza (2020) afirma que, si bien estas no han sido conceptualizadas ni definidas, en las Ordenanzas Metropolitanas 912, 1015, 1076 y 1146 se han determinado parámetros urbanísticos diferenciados para cada una de ellas. Respecto a la racionalidad detrás de este tipo de estructuración urbana, Mendoza (2020) comenta lo siguiente:

La lógica no explícita detrás de la diferenciación de ATNs es el rol que deberían cumplir cada una de ellas según sus condiciones de desarrollo urbano. Así, la ATN I corresponde a las áreas de la ciudad con menor nivel de consolidación, en proceso de desarrollo y que se encuentran a las zonas de la periferia de la ciudad (...). La ATN II, en cambio, corresponde a las áreas de la ciudad que se encuentran consolidadas, concentran la localización de zonas comerciales y de servicios importantes de la ciudad (...). La ATN III también corresponde a porciones de la ciudad con mayor nivel de consolidación y una gran concentración de áreas comerciales y servicios metropolitanos, así mismo, son las porciones de la ciudad con el mayor valor de suelo urbano, sin embargo, son los parámetros urbanísticos limitan la altura y densidad, el índice de usos de suelo es limitado (...). La ATN IV corresponde a todo lo que no es lo anterior, básicamente dos grandes tipos: el centro histórico y las áreas de ocupación semi rural.

Visto de una manera crítica, según la propia Municipalidad de Lima en un documento resumen sobre la propuesta del PLAM2035, en la actualidad las ATN son agrupaciones muy generales que no consideran la complejidad urbana de Lima Metropolitana (Municipalidad Metropolitana de Lima, 2016, p. 26).

Para Fernández (2020), hay dos problemas adicionales que presenta esta estructuración. El primero es que la definición formal de estas áreas de tratamiento normativo no dice nada realmente respecto a su contenido. Para el autor, distinciones como "mayor densificación" o "densificación regulada" no solo son cuestionables, sino que parecen ser una forma de distinguir (tal vez de manera discriminatoria) entre la zona "moderna" de la ciudad a la que se le exige densificar y la zona "no moderna" a la que sí se le impone la densificación. El segundo problema es que parecen ser una manifestación de una pretensión de categorizar en extremo espacios de la ciudad que son inevitablemente heterogéneos. Así, señala Fernández (2020) que:

(...) con las ATNs, por la existencia de alguna cuestionable característica común, un área en el distrito de Comas y una en el distrito de Villa María del Triunfo 


\section{Iván Ortiz Sánchez \\ José Carlos Fernández Salas \\ Andrés Devoto Ykeho}

recibirían la misma regulación. Esto a pesar de lo diferentes que puedan ser estas áreas en sus respectivas dinámicas. Lo mismo cabría decir con respecto al tratamiento de un inmueble en San Isidro y un inmueble en La Molina, que han sido agrupados solo por tener alguna característica en común (posiblemente el valor elevado del suelo)

El tercer y último nivel de clasificación en la ciudad está determinado por la zonificación, clasificación que detallaremos a continuación.

\subsection{Zonificación y Cambios de Zonificación}

A nivel normativo, la zonificación de los usos del suelo se conceptualiza como el instrumento técnico-normativo que orienta, regula y organiza la localización de actividades urbanas en concordancia con los objetivos y políticas de desarrollo metropolitano ${ }^{(9)}$. Este instrumento tiene como finalidad condicionar y reglar el ejercicio del derecho de propiedad predial respecto al uso y ocupación que se le pueda dar y puede decirse que tiene su reconocimiento en el artículo 957 del Código Civil. Es el instrumento que regula de manera más minuciosa y directa las acciones de los propietarios como veremos a continuación.

La Ordenanza 1862 establece que la zonificación regula la densidad urbana (número de personas que pueden habitar en una unidad, metros cuadrados, de superficie urbana) y la intensidad del suelo. Según Ortiz (2017, p. 85), este objetivo estaría basado en la premisa de que el suelo es un recurso escaso y, por lo tanto, se le debe dar una mayor intensidad a su uso en la medida de lo posible. Un ejemplo de la manifestación de este objetivo específico es la regla que prohíbe que, tanto los Reajustes Integrales de Zonificación como los Cambios de Zonificación establezcan zonificaciones con una intensidad menor de uso de los predios.

De igual forma, otro objetivo específico es la integración de actividades urbanas compatibles y flexibilización del uso del suelo. En otras palabras, las normas de zonificación suelen establecer que ciertas actividades pueden aprobarse a pesar de que la zonificación en estricto se haya previsto otro uso. Esto se justifica porque permite la generación de diversidad de usos y edificios en el tejido urbano.

Al final de todo, los múltiples objetivos que pueda tener la zonificación se materializan en tres documentos: (i) Plano de Zonificación de los Usos del Suelo, (ii) Índice de Usos para la Ubicación de Actividades Urbanas y el (iii) Reglamento de Zonificación de los Usos del Suelo. El primero es el documento gráfico que forma parte de los diferentes instrumentos de planificación. El segundo es una lista que define las actividades que es posible realizar en los diferentes sectores, avenidas o calles. Estas actividades que se encuentran en los Índices se establecen de acuerdo a la Clasificación Industrial Internacional-CIIU. Finalmente, tenemos al Reglamento de Zonificación que regula el detalle de los parámetros urbanísticos y edificatorios. Siguiendo el marco del Reglamento Nacional de Edificaciones, estos reglamentos son aquellas disposiciones técnicas que establecen las características que debe tener un proyecto de edificación o de habilitación urbana. Por ejemplo, señala el uso del suelo, las dimensiones del lote normativo, el coeficiente de edificación, la densidad neta de habitantes por hectárea, la altura del lote normativo, retiro, porcentaje del área libre, número de estacionamientos y otras condiciones que debe ser respectadas por los administrados.

A nivel metropolitano(10) existen dos reglamentaciones de parámetros vigentes. Por un lado, el artículo 30 de la Ordenanza 620-MML, que es el único artículo vigente de dicha ordenanza y que contiene disposiciones relativas a la identificación, calificación y características técnicas para el uso del suelo, según las distintas zonas urbanas residenciales, comerciales e industriales. Esta norma debe leerse en concordancia con la posterior Ordenanza 719-MML que incorporó algunos cambios y precisiones. Todo lo señalado está referido a la normativa general a nivel metropolitano, pero no debe perderse de vista que la regulación detallada para cada zona de la ciudad se encuentra en las ordenanzas de reajuste integral de zonificación que existen para los distritos en específico y que son aprobadas por la Municipalidad Metropolitana de Lima.

Por último, tenemos el cuarto nivel de Aspectos Técnicos Complementarios encontrados en normas distritales. Si bien la zonificación es competencia de las Municipalidades Provinciales, existen normas

(9) Artículo 12 de la Ordenanza 1862-MML

(10) El último antecedente de parámetros urbanísticos y edificatorios en Lima son los parámetros generales contenidos en el Reglamento de Zonificación General de Lima Metropolitana aprobados por la Resolución Suprema 045-79-VC-5500. Hay que tomar en cuenta que a la fecha en la que se publicó esta resolución, era de competencia del Ministerio de Vivienda y Construcción realizar y actualizar estudios urbanísticos para el desarrollo de centros poblados del país. 
de elaboración distrital que desarrollan los alcances concretos, así que deben ser tomadas en cuenta para procedimientos administrativos de Anteproyecto en Consulta, Licencias de Edificación y Licencias de Funcionamiento (Chehade, 2008, p. 2010). Los distritos solo por excepción pueden regular aspectos como la zonificación, las alturas y los usos cuando esto se da en el marco de delegaciones dispuestas por la Municipalidad Metropolitana de Lima.

En el caso de nuestra capital se han dado delegaciones en cinco distritos: Miraflores ${ }^{(11)}$, La Molina ${ }^{(12)}$, Santiago de Surco ${ }^{(13)}$, San Isidro(14) y San Borja ${ }^{(15)}$. No obstante, la Municipalidad Metropolitana de Lima ${ }^{(16)}$ hace ya seis años que derogó toda disposición municipal que disponga la delegación de competencias metropolitanas a las municipalidades distritales en materia de organización del uso del suelo, planificación y desarrollo urbano. Esto implica que en la actualidad la competencia en materia de zonificación se encuentra enteramente en la Municipalidad Metropolitana de Lima. Así, hay casos donde los Municipios Distritales han publicado sus Parámetros Urbanísticos Específicos sin tener una delegación de competencias de por medio lo cual determina que estos parámetros sean ilegales. Un ejemplo de ello son los parámetros ilegales de Pueblo Libre ${ }^{(17)}$.

En la actualidad, hay dos vías para proponer nuevas zonificaciones en las áreas conurbadas de nuestra metrópoli. Cada una de estas vías tiene diferentes características, escalas, procedimientos y responsables. Las vías son, además de la propia aprobación de un nuevo plan de desarrollo metropolitano: los Cambios de Zonificación y los Reajustes Integrales de Zonificación General. Tanto la elaboración de planes como los reajustes integrales no pueden ser propuestos por particulares, a diferencia de los Cambios de Zonificación que sí admiten propuestas de entidades públicas como de personas jurídicas privadas.

Los Cambios de Zonificación en Lima están regulados por la Ordenanza 2086. La norma los define como peticiones de gracia que tiene por objeto solicitar de manera excepcional el cambio de zonificación de determinada área. Solo será atendible la petición si coincide con el objetivo de desarrollo de la zona y de la ciudad, análisis que recae en el ente especializado que es el Instituto Metropolitano de Planificación. Sobre la extensión del cambio de zonificación, la Ordenanza 2086 (Artículo 11) solo permite aprobar cambios de un solo predio cuando el cambio sea para Equipamientos Urbanos de Educación, Salud y Otros Usos y en ciertos supuestos especiales debidamente sustentados. La regla será que las modificaciones se hagan extensivas como mínimo a todo el frente de la manzana, a los dos frentes de la vía, a toda la manzana, o al sector urbano en donde se ubica el inmueble materia de la solicitud.

Sobre la naturaleza de petición de gracia, nuestra Constitución ${ }^{(18)}$ reconoce como derecho de toda persona la posibilidad de formular peticiones, individual o colectivamente, por escrito antes la autoridad competente. En este sentido, la Ley del Procedimiento Administrativo General (LPAG) especifica que estas peticiones administrativas comprenden facultades como la de presentar solicitudes de gracia ${ }^{(19)}$. Esta petición viene a ser la facultad por la cual el administrado solicita al titular de la entidad la emisión de un acto sujeto a su discrecionalidad o a su libre apreciación. Los pedidos de cambio de zonificación son peticiones de gracia ya que la Municipalidad de Lima, a pesar de pedir requisitos técnicos, opiniones, y plazos, puede a su libre apreciación aceptar el cambio o no. La zonificación es, al fin y al cabo, un instrumento normativo y no un acto administrativo.

Respecto a los Reajustes Integrales de Zonificación (RIZ), estamos ante el proceso

(11) Artículo 7 de la Ordenanza 920-MML

(12) Artículo 6 de la Ordenanza 1144-MML

(13) Artículo 8 de la Ordenanza 912-MML

(14) Artículo 6 de la Ordenanza 950-MML

(15) Artículo 6 de la Ordenanza 1063-MML

(16) Segunda Disposición Derogatoria de la Ordenanza 1862-MML

(17) Ordenanza 485-MPL

(18) Art. 220

(19) Art 106.2

(20) Por ejemplo, San Miguel, Santa Rosa o San Juan de Lurigancho.

(21) Por ejemplo, el caso del Reajuste Integral del distrito de San Isidro y un sector del distrito de Magdalena del Mar que son parte del Área de Tratamiento Normativo III de Lima Metropolitana.

(22) Por ejemplo, el Reajuste de Punta Hermosa, Punta Negra, Santa María del Mar y Pucusana.

(23) Por ejemplo, el reajuste integral de la zona de reglamentación especial de los Pantanos de Villa. 
técnico de racionalizar la actual calificación adecuándola a la realidad urbanística, constructiva y funcional que hoy en día registra la ciudad metropolitana. En nuestra ciudad, los reajustes pueden hacerse para un solo distrito ${ }^{(20)}$, un distrito y un sector de otro ${ }^{(21)}$, más de dos distritos ${ }^{(22)}$ e incluso puede abarcar un territorio menor a un distrito ${ }^{(23)}$. Como podemos apreciar, a diferencia de los Cambios de Zonificación, estos se hacen en una extensión mucho mayor y a propuesta de la Municipalidad Distrital. El Instituto Metropolitano de Planificación revisa estos Reajustes y luego de un procedimiento de análisis se aprueba un Plano con la nueva Zonificación Distrital mediante Ordenanza del Concejo Metropolitano de Lima. Estas reglas que rigen antes mencionadas también se chocan con una realidad adversa.

\section{Desafíos de la normativa metropolitana de planificación}

Después de haber realizado una revisión de la planificación urbana en el Perú, el marco normativo de la planificación urbana de Lima Metropolitana, en esta parte abordaremos los principales desafíos de las políticas y las normas sobre la planificación urbana metropolitana de Lima.

\subsection{Fragmentación administrativa y falta visión de ciudad} La Municipalidad Metropolitana de Lima tiene 43 distritos más la Provincia Constitucional del Callao que tiene 7 distritos. En total se tienen 50 distritos cada uno con su propio alcalde y su propia estructura administrativa. Existe, por tanto, una gran fragmentación administrativa y de competencias entre el municipio metropolitano y los distritales, así como entre los Municipios de Lima y del Callao. Ello sin contar con la coordinación que se requería tener con otras provincias de la región Lima y con el propio gobierno regional de Lima Provincias.

A nivel comparativo, de las 64 áreas metropolitanas de ciudades de América latina y Caribe estudiadas por Lanfranchi y Bidart (2016, p. 42) podemos afirmar que Lima comparte junto a Belo Horizonte el puesto como la segunda área metropolitana con mayor número de municipios considerados oficialmente, siendo parte del $6 \%$ de casos de áreas metropolitanas con escenarios muy fragmentados.

De otro lado, algo que agrava más esta fragmentación, es que en Lima Metropolitana ha existido delegación de competencias de la Municipalidad Metropolitana sobre aprobación parámetros edificatorios y urbanísticos hacia algunas municipalidades distritales que establecen diferentes criterios y normas, generándose contradicciones y desorden normativo. Además, se ha presentado una problemática de municipios distritales que han realizado estas intervenciones sin delegación de competencias.
Adicionalmente, los problemas de demarcación territorial distrital en Lima Metropolitana presentan un gran desafío, pues los límites jurisdiccionales, determinados por nomas de demarcación territorial, ajenas al urbanismo, dificultan la implementación de medidas de gestión y planificación urbana. Los límites distritales jurisdiccionales no se condicen con los sectores funcionales de la ciudad.

¿Qué tipo de ciudad están promoviendo las normas nacionales y metropolitanas, una ciudad difusa o una ciudad compacta? ¿Hacia dónde debe dirigirse nuestra visión de ciudad y con ello de las políticas y las normas urbanas, la planificación y la gestión urbana? Estas preguntas son esenciales en la planificación metropolitana y deben incorporarse en los instrumentos normativos que Lima requiere.

\subsection{Debilidad institucional de la planificación urbana}

La planificación para Lima ha sido un instrumento débil en la medida que aparentemente, el Estado decidió no asumir el liderazgo del crecimiento de la ciudad, lo que termina favoreciendo la iniciativa privada o informal (Vega et al., 2019, p. 47). El plan de desarrollo (PLANMET) debía estar vigente en Lima hasta el año 2010, por lo que en la gestión de la alcaldesa Susana Villarán se elaboró una propuesta de plan hacia el año 2035 pero que lamentablemente no fue aprobado por el Concejo Metropolitano.

En este contexto, podemos apreciar una debilidad institucional del Instituto Metropolitano de Planificación de Lima. La planificación urbana metropolitana se encuentra debilitada no solamente porque no existe un plan metropolitano vigente, sino porque los organismos que se encargan de la planificación urbana enfrentan desafíos complicados en cuanto a presupuesto y asignación de competencias. Por lo tanto, consideramos de vital importancia el fortalecimiento del Instituto Metropolitano de Planificación de Lima mejorando sus presupuestos y dándole más fuerza en los procesos de aprobación de normas y procedimientos relacionados a la planificación urbana y la zonificación. 
Adicionalmente, consideramos que sería muy importante vincular la planificación urbana y, en especial, la metropolitana, con los presupuestos públicos. Un tema muy importante en las áreas metropolitanas y ciudades de nuestro país es que no se encuentran articulados los presupuestos públicos con los planes urbanos. Es cierto que los presupuestos por incentivos sí se aplican también a nivel metropolitano. Sin embargo, estos presupuestos se centran más que todo en el aspecto de gestión y ejecución de proyectos y no en el aspecto de la elaboración de planes de desarrollo urbanos.

De otro lado, se debe promover una gobernanza metropolitana integrada sobre la base de los principios dispuestos en la Nueva Agenda Urbana de Habitat III. La normativa de planificación urbana metropolitana debe basarse en los principios de equidad, el uso eficaz y sostenible del suelo, la compacidad, el policentrismo, la conectividad y las densidades adecuadas y los múltiples usos del espacio; así como los usos sociales y económicos mixtos en las zonas construidas, a fin de reducir los problemas y las necesidades de movilidad y los costos per cápita de la prestación de servicios y aprovechar la densidad y las economías de escala y de aglomeración (basado en la nueva Agenda Urbana [2016] Hábitat III-Quito).

\subsection{Normativa confusa y desordenada}

Como parece evidente del recuento que se ha hecho en secciones anteriores, las sucesivas modificaciones y derogaciones parciales, así como el tratamiento de la zonificación por distritos han generado una regulación metropolitana confusa y poco clara. No hay sistematización o un equivalente a un texto único ordenado. No hay, tampoco, estudios e investigaciones sobre la calidad regulatoria respecto a la planificación urbana, la zonificación metropolitana o mínimamente sobre la predictibilidad que los administrados buscarían tener para sus actividades.

Un ejemplo es la relación entre las Ordenanzas $1862 \mathrm{MML}$ y $2086 \mathrm{MML}$, pues no existe razón para que se encuentren separadas las regulaciones de los instrumentos de planificación y los cambios de zonificación. Para complicar aún más este problema sigue vigente el artículo 30 de la Ordenanza $620 \mathrm{MML}$ para efectos de los parámetros urbanísticos y edificatorios.

Ante este contexto, es necesario ordenar, integrar, centralizar y sistematizar el marco normativo urbano nacional y metropolitano de la planificación urbana. Es necesario, para ello, un instrumento normativo a nivel nacional como una Ley del Suelo, Ley de Desarrollo Urbano o Código Urbano, así como un instrumento a nivel metropolitano, que vendría a ser una ordenanza metropolitana que ordene, sistematice e integre la planificación urbana, zonificación y las áreas de tratamiento en un solo cuerpo normativo metropolitano.

Consideramos también que se debe establecer la estructuración urbana a través de las áreas de tratamiento normativo. Sin embargo, estas deben actuar como un instrumento para establecer regulaciones urbanas homogéneas con el objetivo de usar las centralidades del área metropolitana de Lima como variable de análisis y superar los límites jurisdiccionales. En tal sentido, en lugar de tener solamente cuatro áreas de tratamiento normativo como se tiene en la actualidad, debería establecerse un área de tratamiento normativo por cada centralidad y su área de influencia que el análisis urbano identifique en la ciudad. Este esquema permitiría hacer una planificación coherente que no se vea limitada por los límites jurisdiccionales de los distritos. Asimismo, una vez aprobado el plan de desarrollo metropolitano, esta sería la escala correcta para el análisis de modificaciones progresivas del plan. Por ejemplo, de darse modificaciones del plan a través de reajustes integrales, lo recomendable no sería hacerlos inorgánicamente sino tomando en cuenta la escala del área de tratamiento normativo. Se evita con ello las decisiones puntuales y aisladas respecto del uso del suelo.

Finalmente, es imprescindible fomentar el fácil acceso y entendimiento de las normas jurídicas de planificación mediante estrategias digitales, interactivas y de sistematización con el propósito de darles legitimidad y predictibilidad. La poca eficacia de los instrumentos legales de planificación en Lima Metropolitana tiene que ver no solo con la falta de normas adecuadas, sino también con la dificultad de acceder a dichas normas. Por ello, se tiene que buscar instrumentos y plataformas por los cuales los usuarios del sistema de planificación que son los ciudadanos puedan acceder a las normas que regulan la planificación de un modo que permita su familiaridad y entendimiento de las mismas. Esta es una tarea que se debe desarrollar tanto en la producción de futuras normas como también en la sistematización de las normas actuales.

La sistematización y ordenación de las normas no solamente ayudará a los ciudadanos sino también a las funciones que cumplen la Municipalidad Metropolitana de Lima y, en particular, el Instituto Metropolitano de Planificación. Procesos como los de aprobación de licencias o cambios de 


\section{Iván Ortiz Sánchez \\ José Carlos Fernández Salas \\ Andrés Devoto Ykeho}

zonificación se beneficiarán de tener normas sistematizadas y en plataformas que sean accesibles por distintos profesionales. Lo propio sucederá con el proceso de desarrollo de un plan metropolitano y sus respectivas actualizaciones hacia futuro.

Presentamos a modo de resumen un árbol de problemas elaborado por los autores del presente artículo:

\section{Árbol de Problemas}

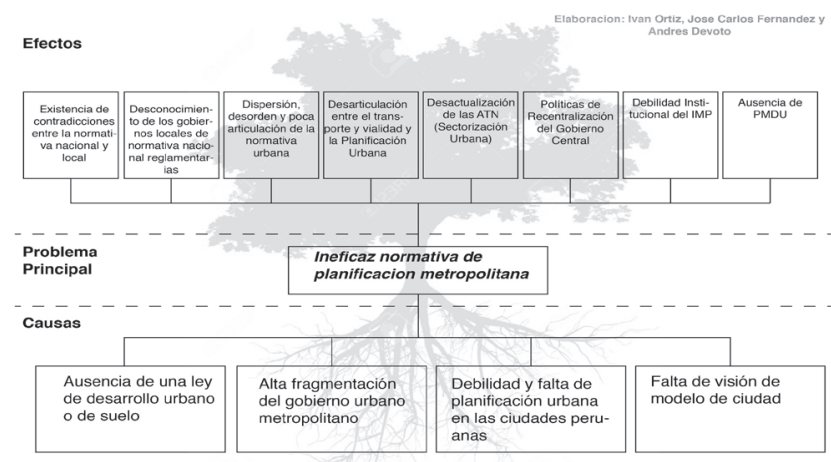

\section{Reflexiones finales}

La planificación urbana es esencial para un desarrollo ordenado y sostenible de las ciudades. Esta, además, constituye una función pública como parte importante del rubro del urbanismo y como expresión del ordenamiento territorial que se prevé en nuestra constitución política vigente. En el ámbito jurídico lo dicho se materializa a través de las distintas instituciones jurídicas que forman parte del campo del derecho urbanístico.

Como se ha descrito, la planificación urbana en el Perú está compuesta por diversos tipos de planes de desarrollo como el plan de acondicionamiento territorial, el plan de desarrollo metropolitano y el plan de desarrollo urbano. La función pública de la elaboración y aprobación de estos planes es competencia municipal provincial y son aprobadas por ordenanzas municipales, es decir, son instrumentos que tienen naturaleza normativa. El instrumento central de los planes para asignar y ordenar los usos del suelo es la zonificación.

En el desarrollo de nuestra investigación, concluimos que la normativa y el marco jurídico de planificación urbana metropolitana de Lima enfrenta diversos desafíos críticos: la fragmentación administrativa, la falta de visión de ciudad, la debilidad institucional y la carencia de sistematicidad en la normativa.

La fragmentación del gobierno urbano metropolitano de Lima se expresa en la ausencia de un gobierno metropolitano sobre el área de Lima-Callao, con la conjunción de diversos gobiernos regionales, municipales y 50 municipios distritales que participan en la gestión urbana metropolitana. Se tiene también una falta de visión de un modelo de ciudad para el área metropolitana de LimaCallao que ordene y oriente la acción pública y privada sobre el suelo urbano. Por otra parte, la planificación urbana en el Perú es débil, según datos del Ministerio de Vivienda, Construcción y Saneamiento (Navarro Franco, 2020) dado que solo $46 \%$ de los municipios tienen plan de acondicionamiento territorial y $13 \%$ tienen plan de desarrollo urbano.

Además, Lima, la capital del país y el espacio en que habita la tercera parte de la población nacional, carece de un plan metropolitano de desarrollo vigente desde el año 2010. La normativa metropolitana de Lima sobre planificación urbana y zonificación es confusa y desordenada pues presenta una carencia de sistematicidad de las normas. Así, las ordenanzas metropolitanas que regulan dichas funciones públicas deben ser articuladas e integradas en un cuerpo normativo unitario y orgánico.

Aunque el objetivo de este texto ha sido el de comenzar con un diagnóstico del marco regulatorio de la planificación urbana en Lima Metropolitana, aquí planteamos algunos lineamentos introductorios que seguiremos desarrollando como parte de esta investigación. Estos lineamientos buscan aportar al debate y discusión de políticas públicas para superar los desafíos críticos de la normativa de planificación urbana de Lima Metropolitana:

- Consideramos necesario ordenar, integrar, centralizar y sistematizar el marco normativo urbano nacional, a través de una Ley del Suelo y el marco normativo metropolitano de la planificación urbana a través de una Ordenanza que integre la planificación y zonificación metropolitana en un marco normativo integrado $y$ sistematizado.

- En el mismo sentido, a nivel nacional será importante fortalecer el principio de subordinación del interés privado al interés general que se exprese en limitaciones del derecho de propiedad sobre el suelo al bien común por razones del urbanismo y el ordenamiento territorial en el marco constitucional y evaluar 
la incorporación del derecho a la ciudad en nuestro ordenamiento jurídico.

- Fortalecer el Instituto Metropolitano de Planificación de la Municipalidad Metropolitana de Lima. Además, creemos que se debe vincular la planificación urbana y, en especial, la metropolitana con los presupuestos públicos.

- Desarrollar una institucionalidad pública adecuada que supere la fragmentación del gobierno del área conurbana de Lima y Callao y permita una planificación urbana con una escala adecuada y eficaz. Asegurar la articulación de la Municipalidad Metropolitana de Lima con entidades que generen coordinación entre los ámbitos como la Autoridad Única de Transporte y SEDAPAL, a fin de armonizar sus intervenciones e inversiones relacionadas a la provisión de servicios e infraestructura pública con las estrategias de densificación urbana en la conurbación.

- Fomentar el fácil acceso y entendimiento de las normas jurídicas de planificación mediante estrategias digitales, interactivas y de sistematización con el propósito de darles legitimidad y predictibilidad.

- Repensar la normativa urbana metropolitana en el contexto de informalidad que atraviesa nuestra capital. Al igual que la mayoría de las ciudades peruanas ${ }^{(24)}$, Lima cuenta con preocupantes cifras de informalidad. El $90 \%$ de la expansión urbana de Lima ha sido informal, es decir mediante lotizaciones informales y ocupaciones ilegales (Espinoza y Fort 2020, p.17). En la actualidad el 54\% del Área Metropolitana de Lima está ocupada por asentamientos humanos surgidos de estas ocupaciones (Torres 2018, p.15). Respecto a las edificaciones, 7 de cada 10 viviendas han sido construidas de manera informal ${ }^{(25)}$. Por lo tanto, se debe tomar en cuenta que la normativa actualmente aplica para una cantidad reducida de personas y, no solo se necesita mayor nivel de cumplimiento, sino que se debe buscar acercar la normativa a la realidad urbana.

Finalmente, es importante terminar de elaborar el plan de desarrollo metropolitano al 2040 , en cuyo proceso se encuentra la Municipalidad Metropolitana de Lima, a fin de que sea participativo y democrático y oriente la gestión metropolitana municipal hacia un desarrollo urbano sostenible. Nuestra gestión municipal no puede continuar sin un plan que oriente el desarrollo en Lima metropolitana hacia el futuro.

\section{Referencias bibliográficas}

Calderón, J. (2017). La insoportable levedad de la Planificación Urbana y lo legal informal en el Perú. El arte del desgobierno. Serie: Perú Hoy (31), 221-235. http://www.desco.org.pe/recursos/site/files/ CONTENIDO/1118/12_Calderon_PHj17.pdf

Castillo, R. (2013). La planificación urbana de Lima - Callao 1949 - 2013: del urbanismo funcionalista a la planificación del Desarrollo Urbano Sostenible. Paideia XXI3(4), 20-32. https://revistas.urp.edu.pe/ index.php/Paideia/article/view/925/842

Chehade, R. (2008, 5 de julio). El nuevo uso de los suelos en Lima. Diario El Comercio. http://www. ipdu.pe/web/index.php/actualidad/articulos/290el-nuevo-uso-de-los-suelos-en-lima

Espinoza, A. y Fort, R. (2020). Mapeo y tipología de la expansión urbana en el Perú. GRADE.

Fernández, J. (2018). 3D Titling: Comments on the Introduction of the Transfer of Development Rights to Peru. Latin America Policy Journal (8). https:// lapj.hkspublications.org/3d-titling-comments-peru/

Fernández, J. (2020). Las Áreas de Tratamiento Normativo de Lima y el Cientificismo de la Planificación Urbana. Enfoque Derecho. https:// www.enfoquederecho.com/2020/05/04/lasareas-de-tratamiento-normativo-de-lima-y-elcientificismo-de-la-planificacion-urbana/

Fernández, J. y Pinedo, K. (2020). Entre la visión civil y la visión urbanística del derecho de propiedad: apuntes sobre el caso del Hotel Sheraton del Cusco. En Puertas Villavicencio, Gonzalo et al. (Coord.). Propiedad. Enfoque Urbanístico y Registral. Themis Editorial Jurídica.

Instituto Metropolitano de Planificación (2020). Modelo de Desarrollo Urbano y Territorial: Plan Metropolitano de Desarrollo Urbano Lima al 2040 [presentación de diapositivas].

Kahatt, S. (2015). Utopías Construidas, Las Unidades Vecinales de Lima. Fondo Editorial PUCP.

Lafranchi, G \& M Bidart. (2016). Gobernanza metropolitana en América Latina y el Caribe. Centro de Implementación de Políticas Públicas para Equidad y el Crecimiento. https://www.cippec.org/ wp-content/uploads/2017/03/1069.pdf

(24) Según últimos estudios de Espinoza y Fort, el $93 \%$ del nuevo suelo urbano creado desde el 2001 corresponde a urbanizaciones informales, es decir asentamientos que no cuenten con habilitación urbana completa (2020, p. 10).

(25) Informalidad en el sector construcción: ¿Por qué las edificaciones se caen? ¿Cómo evitarlo? https://rpp.pe/seamos-peruanos-decalidad/informalidad-en-el-sector-construccion-por-que-las-edificaciones-se-caen-como-evitarlo-noticia-1078284 


\section{Iván Ortiz Sánchez \\ José Carlos Fernández Salas \\ Andrés Devoto Ykeho}

Mendoza, A. (2020, 12 de enero). La regulación urbanística de la provincia de Lima. Urbanismo y Economía. https://urbanismoyeconomia.wordpress. com/2020/01/12/la-regulacion-urbanistica-de-laprovincia-de-lima/

Municipalidad Metropolitana de Lima. Plan Metropolitano de Desarrollo Urbano PLAM [presentación de diapositivas]. Municipalidad Metropolitana de Lima. http://www.munlima.gob. pe/images/descargas/region-lima/asambleametropolitana/PLAN-METROPOLITANO-DEDESARROLLO-URBANO.pdf

Navarro, H. (2020). Taller de Presentación de la Propuesta de Política Nacional de Vivienda, Urbanismo y Desarrollo Sostenible. Universidad del Pacífico.

Ortiz, I. (2017). Introducción al Derecho Urbanístico. Fondo Editorial PUCP.
Ortiz, I. (2019). Los planes urbanos en nuestro ordenamiento jurídico y el Tribunal Constitucional. Revista Gaceta Constitucional 138. (pp. 119-129).

SPDA Actualidad Ambiental (2020). Organizaciones sociales solicitan a la Municipalidad de Lima no cambiar zonificación del valle de Lurín. SPADA Actualidad Ambiental. https://www.actualidadambiental.pe/ organizaciones-sociales-solicitan-a-la-municipalidad-de-lima-nocambiar-zonificacion-del-valle-de-lurin/

Torres, D. (2018). Titulación de tierras sin ciudad, del bien colectivo al privado. Universidad Nacional Autónoma de México.

Vega, P., Dammert, M., Moschella, P., Vilela, M., Bensus, V., Fernandez de Cordova, G. y Pereyra, O. (2019). Las Centralidades de Lima Metropolitana en el Siglo XXI. Una Aproximación empírica. Facultad de Arquitectura y Urbanismo PUCP.

Zucchetti, A. y Freundt,D.(2019). Ciudades del Perú: Primer Reporte Nacional de Indicadores Urbanos 2018. Periferia. 


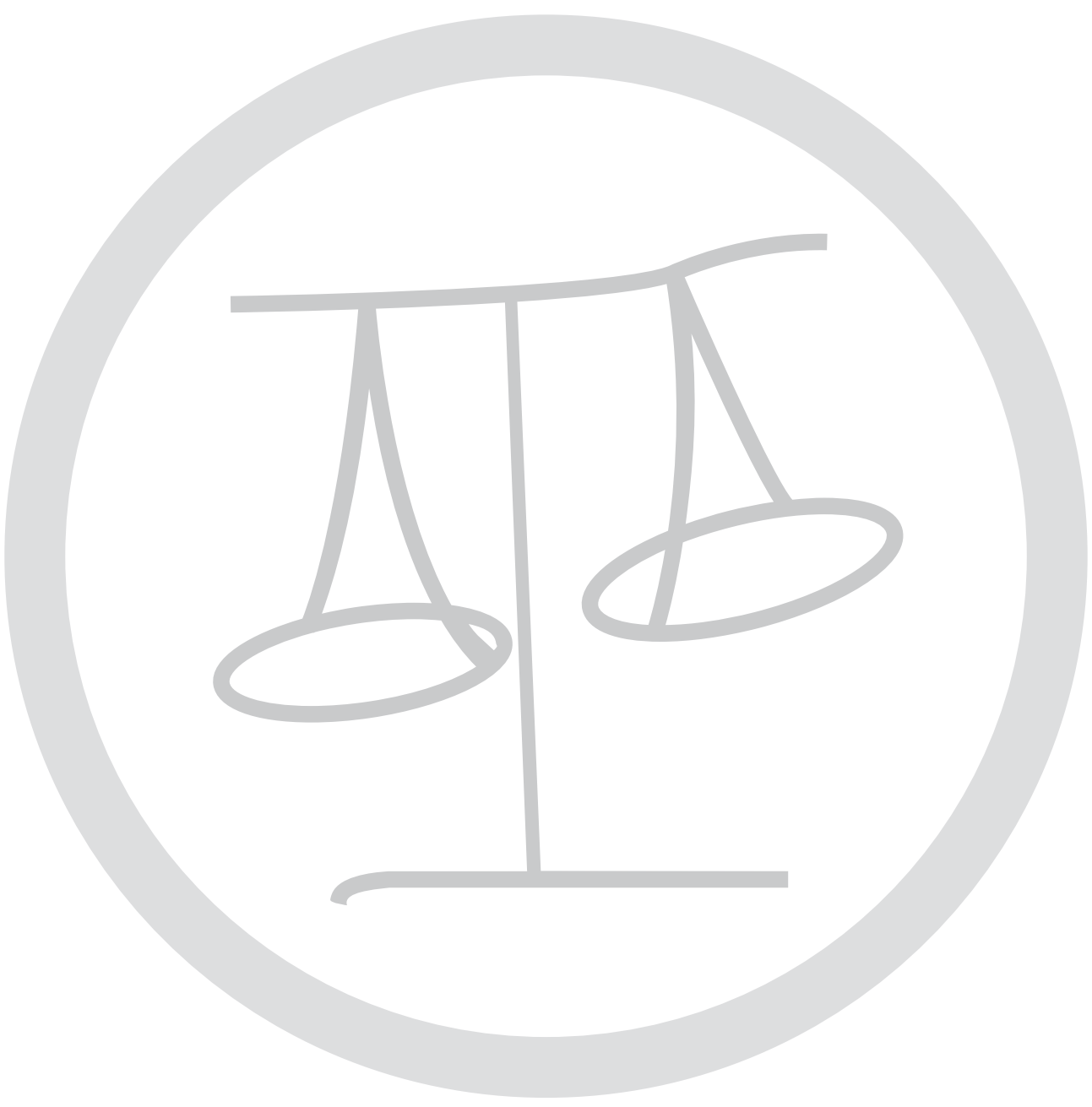

